\title{
Pharmaceutical Characterization of Tropomyosin Receptor Kinase B-Agonistic Antibodies on Human Induced Pluripotent Stem (hiPS) Cell-Derived Neurons ${ }^{[\mathbf{S}}$
}

\author{
Stefanie Traub, Heiko Stahl, Holger Rosenbrock, Eric Simon, Lore Florin, Lisa Hospach, \\ Stefan Hörer, and Ralf Heilker \\ Trenzyme GmbH, Konstanz (S.T.) Germany, Lead Identification and Optimization Support (L.H., S.H., R.H.), Immunological and \\ Respiratory Diseases Research (H.S.), CNS Diseases Research (H.R.), and Target Discovery Research (E.S.), Boehringer \\ Ingelheim Pharma GmbH \& Co. KG, Biberach, Germany; and Biotherapeutics Discovery, Boehringer Ingelheim Pharmaceuticals \\ Inc., Ridgefield, Connecticut (L.F.)
}

Received January 10, 2017; accepted March 23, 2017

\begin{abstract}
Brain-derived neurotrophic factor (BDNF) is a central modulator of neuronal development and synaptic plasticity in the central nervous system. This renders the BDNF-modulated tropomyosin receptor kinase $B$ (TrkB) a promising drug target to treat synaptic dysfunctions. Using GRowth factor-driven expansion and INhibition of $\mathrm{NotCH}(\mathrm{GRINCH})$ during maturation, the so-called GRINCH neurons were derived from human-induced pluripotent stem cells. These GRINCH neurons were used as model cells for pharmacologic profiling of two TrkB-agonistic antibodies, hereafter referred to as $A B 2$ and $A B 20$. In next-generation sequencing studies, $A B 2$ and $A B 20$ stimulated transcriptional changes, which extensively overlapped with BDNF-driven transcriptional modulation. In regard to TrkB phosphorylation, both $A B 2$ and $A B 20$ were only about half as efficacious as BDNF; however, with respect to the TrkB downstream signaling, $A B 2$ and $A B 20$
\end{abstract}

displayed increased efficacy values, providing a stimulation at least comparable to BDNF in respect to VGF transcription, as well as of AKT and CAMP response element-binding protein phosphorylation. In a complex structure of the TrkB-d5 domain with AB20, determined by X-ray crystallography, the AB20 binding site was found to be allosteric in regard to the BDNF binding site, whereas $A B 2$ was known to act orthosterically with BDNF. In agreement with this finding, AB2 and AB20 acted synergistically at greater concentrations to drive TrkB phosphorylation. Although TrkB downstream signaling declined faster after pulse stimulation with $A B 20$ than with $A B 2, A B 20$ restimulated TrkB phosphorylation more efficiently than $A B 2$. In conclusion, both antibodies displayed some limitations and some benefits in regard to future applications as therapeutic agents.

\section{Introduction}

Nerve growth factor (NGF), brain-derived neurotrophic factor (BDNF) (Barde et al., 1982), neurotrophin (NT)-3 (NT3), and NT4 represent the NT family of growth factors, acting on tropomyosin receptor kinase (Trk)A, TrkB, TrkC, and p75 NT receptor (Bothwell, 2014). Although all four NTs are agonists for p75NTR, they display some selectivity in regard to the Trk receptors: NGF is a preferential agonist for TrkA, NT3 for TrkC, and BDNF and NT4 for TrkB (Bothwell, 2014). Among the NTs, BDNF stands out for its high expression levels in the central nervous system (CNS) and its effects on synaptic plasticity (Adachi et al., 2014). Accordingly, BDNF has been implicated in a multitude of CNS-related diseases (Adachi et al., 2014) such as Alzheimer disease, Parkinson

https://doi.org/10.1124/jpet.117/240184.

S This article has supplemental material available at jpet.aspetjournals.org. disease, schizophrenia, depression, bipolar disorder, anxiety, Huntington disease, stroke, epilepsy, eating disorders, and substance use.

Therefore, pharmacologic stimulation of TrkB holds the potential for the treatment of various CNS disorders (Longo and Massa, 2013); however, the dimensions of the BDNF dimer and its cognate binding sites on TrkB are beyond what can typically be bridged by a small molecule (Longo and Massa, 2013). Yet, since there are possibilities (Pardridge, 2012) to shuttle a new biologic entity across the blood-brain barrier (BBB), a bivalent biopharmaceutical agent, such as an agonistic antibody against TrkB, could drive receptor dimerization and its transphosphorylation in manner similar to that of the dimeric physiologic TrkB agonist BDNF. Accordingly, in this work, we analyzed two antibodies, AB2 and AB20 (Lin et al., 2010; Wang et al., 2010), directed against extracellular epitopes of TrkB.

ABBREVIATIONS: AKT kinase, Ak strain thymoma kinase; BBB, blood-brain barrier; BDNF, brain-derived neurotrophic factor; CHO, Chinese hamster ovary; CNS, central nervous system; CREB, cAMP response element-binding protein; DPBS, Dulbecco's phosphate-buffered saline; ERK, extracellular signal-regulated kinase; GRINCH, GRowth factor-driven expansion and INhibition of NotCH; hiPS cells, human induced pluripotent stem cells; NGF, nerve growth factor; NGS, next-generation sequencing; NT, neurotrophin; RT-PCR, reverse-transcription polymerase chain reaction; TBS, Tris-buffered saline; Trk, tropomyosin receptor kinase. 
In regard to the ultimate target cells of biopharmaceutical TrkB modulators, an ideal in vitro model system would use human neurons. Such cells express TrkB and downstream signaling components in physiologic amounts and correct stoichiometric ratios. Although access to primary human neurons is obviously limited, the advent of human induced pluripotent stem (hiPS) cell technology has enabled the differentiation toward neuronal target cells in huge numbers, for instance, the so-called GRINCH (GRowth factor-driven expansion and INhibition of NotCH neurons) (Heilker et al., 2014; Traub et al., 2017).

Whereas the endogenous expression levels of TrkB- and TrkB-associated signaling biomolecules in GRINCH neurons represent a better physiologic recapitulation of the in vivo systems, it is much more challenging to measure the respective pharmacologic responses than in a recombinant system. To address this challenge, we used the highly sensitive amplified luminescent proximity homogeneous assay LISA (AlphaLISA) format (Cauchon et al., 2009) and an HTSadapted version of reverse-transcription polymerase chain reaction (RT-PCR). (Traub et al., 2017).

For the pharmacologic profiling of drug candidates, it is important to monitor one of the disease-relevant signaling events associated with the drug target (Heilker et al., 2014). In this work, we compared the efficacies of BDNF, AB2, and AB20 in regard to: 1) TrkB phosphorylation; 2) TrkB downstream signaling modulators extracellular signal-regulated kinase (ERK), Ak strain thymoma kinase (AKT), and cAMP response element-binding protein (CREB); and 3) the TrkBdriven transcription of the synaptic plasticity marker VGF mRNA as an early response gene (Alder et al., 2003). Thus, the applied experimental profiling panel monitors drug efficacy checkpoints all along the signaling chain from the drug target TrkB toward $V G F$ as a disease-relevant biomarker endpoint.

\section{Materials and Methods}

\section{BDNF and Agonistic Antibodies}

BDNF was purchased from Biotrend Chemikalien GmbH (cat. no. CYT-207; Cologne Germany) with a molecular weight of 26,984 Da for the homodimer. AB2 was derived from the previously described antibody $\mathrm{C} 2$ (Lin et al., 2010). In AB2, the humanized $\mathrm{V}$ regions of $\mathrm{C} 2$ were grafted onto the constant regions of a human IgG1 antibody. AB20 was derived from the previously described antibody C20 (Wang et al., 2010) by grafting the murine $\mathrm{V}$ regions of $\mathrm{C} 20$ onto the constant regions of a human IgG1 antibody. Isotype-matched control anti-2,4,6 trinitrophenyl antibody (IgG, derived from 1B7.11; American Type Culture Collection, Rockville, MD) was used as reference. Fc-mediated effector functions of all antibodies were reduced by mutating leucines 234 and 235 to alanines (Xu et al., 2000).

\section{HiPS Cell Maintenance Culture and Neuronal Differentiation}

The minicircle hiPS cell line (cat. no. SC301A-1) was purchased from System Biosciences (Mountain View, CA). HiPS cell maintenance culture, neural induction, neural progenitor cell expansion, and final neuronal differentiation toward GRINCH neurons were carried out as described previously (Traub et al., 2017).

\section{CellSensor Cell Lines}

CellSensor Chinese hamster ovary K1 (CHO-K1) cell lines, which are stably cotransfected with: 1 ) a gene encoding a nuclear factor of activated T cell promoter-regulated $\beta$ lactamase reporter and 2) a gene encoding TrkA (cat. no. K1516), TrkB (cat. no. K1491), or TrkC (cat. no. K1491) were purchased from Life Technologies (Carlsbad, CA). The three cell lines are hence referred to as $C H O-T r k A / B / C$ cells, respectively. The cells were cultured according to the manufacturer's instructions. For the 384-well Alpha assays and immunofluorescence staining, the cells were seeded at a concentration of $100,000 \mathrm{cells} / \mathrm{cm}^{2}$ into one well of a black PureCoat amine-coated 384-well plate (cat. no. 359324; Corning Inc., Corning, NY), and cultured for 24 hours.

\section{Next-Generation Sequencing}

Next-generation sequencing (NGS) was carried out as described in the Supplemental Material.

\section{RT-PCR from Nonpurified Cellular Lysate}

Stimulation of TrkB Signaling for the RT-PCR Format. The supernatant of the 384-well microplates containing the 6,000 GRINCH neurons/well (hereafter referred to as the cell plate) was aspirated to a residual volume of $10 \mu \mathrm{l} /$ well using a BioTek EL406 Washer Dispenser (BioTek, Winooski, VT). Stimulation buffer consisted of $1 \times$ Dulbecco's phosphate-buffered saline (DPBS), supplemented with $1 \%(\mathrm{w} / \mathrm{v})$ bovine serum albumin (cat. no. A3059-100g; Sigma-Aldrich, St. Louis, MO). An equal volume of $10 \mu \mathrm{l} /$ well of stimulation buffer containing BDNF, AB2, AB20, or IgG control was added to the cellular supernatant, producing the indicated final concentrations. The cells were then incubated for 6 hours at $37^{\circ} \mathrm{C}$ and $5 \% \mathrm{CO}_{2}$.

For pathway inhibition experiments, $10 \mu \mathrm{l} /$ well of $20 \mu \mathrm{M} \mathrm{K} 252 \mathrm{a}$, $100 \mu \mathrm{M}$ PD98059, $50 \mu \mathrm{M}$ LY294002, or $100 \mu \mathrm{M}$ U73122 diluted in stimulation buffer supplemented with $2 \%$ DMSO was added to the cellular supernatant before agonist addition. After incubating for 30 minutes at $37^{\circ} \mathrm{C}$ and $5 \% \mathrm{CO}_{2}$ with one of the small-molecule inhibitors, $20 \mu \mathrm{l} /$ well of the indicated agonist diluted in stimulation buffer was added, resulting in final concentrations of $100 \mathrm{ng} / \mathrm{ml} \mathrm{BDNF}$ (3.7 nM), $100 \mathrm{ng} / \mathrm{ml} \mathrm{AB2}(0.66 \mu \mathrm{M})$, and $100 \mathrm{ng} / \mathrm{ml} \mathrm{AB20}(0.66 \mu \mathrm{M})$. The cells were then incubated for 6 hours at $37^{\circ} \mathrm{C}$ and $5 \% \mathrm{CO}_{2}$.

Cell Lysis and VGF Gene Expression Measurement in the RT-PCR Format. After 6 hours of stimulation, the GRINCH neurons were washed three times with $70 \mu \mathrm{l} /$ well $1 \times$ DPBS, and the supernatant was aspirated to a residual volume of $10 \mu \mathrm{l} /$ well using a BioTek EL406 washer dispenser. Subsequently, the cells were lysed for 5 minutes at room temperature using $10 \mu \mathrm{l} /$ well $1 \times$ Realtime Ready cell lysis buffer, supplemented with $2 \times$ RNase inhibitor (cat. no. 05943523001, Realtime Ready cell lysis kit; Roche, Basel, Switzerland). Next, $9 \mu \mathrm{l} /$ well Realtime ready master mix, composed of $1 \times$ Realtime Ready virus master (cat. no. 05992877001; Roche) and $1 \times$ Realtime Ready Catalogue (cat. no. 05532957001, Roche) primer probe set for VGF (Assay ID: 146837) was prepared and transferred into a 384-well LightCycler 480 plate (cat. no. 04729749001; Roche). Then $1 \mu \mathrm{l} /$ well of the lysate was transferred from the cell plate to the 384-well LightCycler 480 plate using the CyBi-Well Vario 384 Channel Simultaneous Pipettor (Cybio, Jena, Germany). The LightCycler 480 plate was sealed and centrifuged for 4 minutes at $1500 \mathrm{~g}$. Gene expression was measured using a LightCycler 480 instrument. The following RT-PCR program was used: 1 ) reverse transcription: $50^{\circ} \mathrm{C}$, 8 minutes, one cycle; 2 ) preincubation: $95^{\circ} \mathrm{C}, 30$ seconds, one cycle; 3 ) amplification: $95^{\circ} \mathrm{C}, 1$ second, followed by $60^{\circ} \mathrm{C}, 20$ seconds, 45 cycles; and 4) cooling: $40^{\circ} \mathrm{C}, 30$ seconds, one cycle.

\section{AlphaLISA Format}

Stimulation of TrkB Signaling for the AlphaLISA Format. The supernatant of the 384-well microplates containing the 6,000 GRINCH neurons/well or 10,000 CHO-TrkA/B/C cells/well (hereafter referred to as the cell plate) was aspirated to a residual volume of $10 \mu \mathrm{l} /$ well using a BioTek EL406 washer dispenser. An equal volume of $10 \mu \mathrm{l} /$ well of BDNF, AB2, AB20, or IgG control in stimulation buffer was added for 15 minutes at $37^{\circ} \mathrm{C}$ and $5 \% \mathrm{CO}_{2}$, resulting in the respectively indicated concentrations of agonists. For synergism 
experiments, the GRINCH neurons were stimulated for 15 minutes at $37^{\circ} \mathrm{C}$ and $5 \% \mathrm{CO}_{2}$ with combinations of BDNF and $\mathrm{AB} 2, \mathrm{BDNF}$ and $\mathrm{AB} 20$ or $\mathrm{AB} 2$ and $\mathrm{AB} 20$ at the indicated concentrations.

For pathway inhibition experiments, $10 \mu \mathrm{l} /$ well of $20 \mu \mathrm{M} \mathrm{K} 252 \mathrm{a}$, $100 \mu \mathrm{M}$ PD98059, $50 \mu \mathrm{M}$ LY294002, or $100 \mu \mathrm{M}$ U73122 diluted in stimulation buffer were added to the cellular supernatant before agonist addition. After incubating for 30 minutes at $37^{\circ} \mathrm{C}$ and $5 \% \mathrm{CO}_{2}$ with one of the small-molecule inhibitors, $20 \mu \mathrm{l} /$ well of the indicated agonist diluted in stimulation buffer was added, resulting in final concentrations of $10 \mathrm{ng} / \mathrm{ml} \mathrm{BDNF}(0.37 \mathrm{nM}), 100 \mathrm{ng} / \mathrm{ml} \mathrm{AB2}(0.66 \mu \mathrm{M})$, and $1 \mu \mathrm{g} / \mathrm{ml} \mathrm{AB20}(6.67 \mu \mathrm{M})$. The cells were then incubated for 15 minutes at $37^{\circ} \mathrm{C}$ and $5 \% \mathrm{CO}_{2}$.

To analyze the kinetics of TrkB signaling pathways after stimulation with $\mathrm{BDNF}, \mathrm{AB} 2$, or $\mathrm{AB} 20$, three different stimulation schemes were applied. All incubations were carried out at $37^{\circ} \mathrm{C}$ and $5 \% \mathrm{CO}_{2}$. For the restimulation scheme, the GRINCH neurons were stimulated for 15 minutes with $10 \mathrm{ng} / \mathrm{ml} \mathrm{BDNF}(0.37 \mathrm{nM}), 100 \mathrm{ng} / \mathrm{ml} \mathrm{AB2}(0.66 \mu \mathrm{M})$, or $1 \mu \mathrm{g} / \mathrm{ml} \mathrm{AB20}(6.67 \mu \mathrm{M})$ in stimulation buffer and then washed three times with $70 \mu \mathrm{l} /$ well neural differentiation medium (Traub et al., 2017), incubated for the indicated variable intermittent phase in the absence of an agonist, and subsequently stimulated again for 15 minutes until cellular lysis with the same concentrations of BDNF, AB2, orAB20 as administered before the intermittent phase. For the single-pulse scheme, the GRINCH neurons were stimulated for 15 minutes with $10 \mathrm{ng} / \mathrm{ml}$ $\operatorname{BDNF}(0.37 \mathrm{nM}), 100 \mathrm{ng} / \mathrm{ml} \mathrm{AB2}(0.66 \mu \mathrm{M})$, or $1 \mu \mathrm{g} / \mathrm{ml} \mathrm{AB20}(6.67 \mu \mathrm{M})$ in stimulation buffer and then washed three times with $70 \mu \mathrm{l} /$ well neural differentiation medium, incubated for the indicated variable time in the absence of an agonist. For the continuous stimulation scheme, the GRINCH neurons were stimulated for the indicated variable time periods with $10 \mathrm{ng} / \mathrm{ml} \mathrm{BDNF}(0.37 \mathrm{nM}), 100 \mathrm{ng} / \mathrm{ml} \mathrm{AB2}(0.66 \mu \mathrm{M})$, or $1 \mu \mathrm{g} / \mathrm{ml}$ $\mathrm{AB} 20(6.67 \mu \mathrm{M})$.

Cell Lysis. After stimulation, GRINCH neurons or CHO-TrkA/B/C cells were washed three times with $70 \mu \mathrm{l} /$ well $1 \times \mathrm{DPBS}$, and the supernatant was aspirated off to a residual volume of $10 \mu \mathrm{l} /$ well using a BioTek EL406 washer dispenser (BioTek). Subsequently, the cells were lysed for 5 minutes at room temperature by the addition of $10 \mu \mathrm{l} /$ well $1 \times$ Cell Signaling Technology lysis buffer (cat. no. 9803; Cell Signaling Technology, Danvers, MA), supplemented with $2 \times$ protease inhibitor (cat. no. 11873580001; Roche, Basel, Switzerland) and $2 \times$ phosphatase inhibitor cocktails 2 and 3 (cat. no. P5726, cat. no. P0044; SigmaAldrich).

Trk Phosphorylation Measured in the Alpha Format. Custommade Alpha reagents were used to measure Trk phosphorylation: AlphaLISA Acceptor beads (cat. no. 6772003; PerkinElmer, Hopkinton, MA) were conjugated with an antiphosphorylated Trk (pTrk) antibody (cat. no. 4621BF; Cell Signaling Technology), which nonselectively detects TrkA, TrkB, or TrkC phosphorylated at the tyrosine, homologous to Tyr706 in TrkB. 1) For the selective detection of phosphorylated TrkB (pTrkB), the prepared Acceptor beads were used together with a biotinylated, isoform-selective anti-TrkB antibody (cat. no. MAB3971; R\&D Systems Inc., Minneapolis, MN) and streptavidin-coated Alpha Donor beads (cat. no. 6760002B; PerkinElmer). 2) For the nonselective detection of all three phosphorylated Trk isoforms, the prepared Acceptor beads were used together with a biotinylated, anti-pan-Trk antibody (cat. no. 4609BF; Cell Signaling Technology) and streptavidin-coated Alpha Donor beads.

Using these Alpha reagents, $5 \mu \mathrm{l} /$ well of the produced cellular lysate was transferred into the corresponding well of a 384-well smallvolume, flat-bottom plate (cat. no. 784075; Greiner Bio-One GmbH, Frickenhausen, Germany) for Alpha detection using a CyBi-Well Vario 384-channel simultaneous pipettor. Subsequently, $2.5 \mu \mathrm{l} /$ well of the anti-pTrk Acceptor beads (final concentration: $10 \mu \mathrm{g} / \mathrm{ml}$ ), diluted in $1 \times$ AlphaLISA assay buffer (cat. no. AL000F; PerkinElmer), was added. The microplate was incubated for 45 minutes at room temperature. Subsequently, $2.5 \mu \mathrm{l} /$ well of the respective biotinylated antibody (final concentration: $1 \mathrm{nM}$, diluted in $1 \times$ AlphaLISA assay buffer) was added. The microplate was incubated for 45 minutes at room temperature. Finally, $2.5 \mu \mathrm{l} /$ well of Alpha streptavidin-coated
Donor beads (final concentration: $20 \mu \mathrm{g} / \mathrm{ml}$, diluted in $1 \times$ AlphaLISA assay buffer) was added under subdued light conditions. The microplate was incubated for 30 minutes at room temperature in the dark. The AlphaLISA signal was measured using an Envision reader (extinction: $680 \mathrm{~nm} / \mathrm{emission}$ : $615 \mathrm{~nm}$ ) purchased from PerkinElmer.

Phosphorylation of ERK, AKT, or CREB Measured in the Alpha Format. For detection of ERK, AKT, and CREB phosphorylation, AlphaScreen Surefire kits for pERK 1/2 (Thr202/Tyr204; catalog n TGRES50K, PerkinElmer), pAKT 1/2/3 (Ser473; cat. no. TGRA4S50K, PerkinElmer), and pCREB (Ser133; cat. no. TGRCBS50K, PerkinElmer) were used with the generated cellular lysates according to the manufacturer's instructions.

\section{Immunofluorescence Staining of CHO-TrkA/B/C Lines}

The CHO-TrkA/B/C cells were stimulated for 15 minutes at $37^{\circ} \mathrm{C}$ and $95 \% \mathrm{CO}_{2}$ with $10 \mu \mathrm{g} / \mathrm{ml} \mathrm{AB2}$ or AB20. Subsequently, the cells were washed three times with $1 \times$ Tris-buffered saline (TBS; cat. no. T59121L; Sigma-Aldrich) and then fixed with $4 \%(\mathrm{v} / \mathrm{v})$ paraformaldehyde solution (cat. no. 252549-500; Sigma-Aldrich) for 15 minutes at room temperature. Next, the cells were washed three times with $1 \times$ TBS and incubated with $10 \%(\mathrm{v} / \mathrm{v})$ fetal bovine serum (cat. no. 26140-079; Life Technologies) in $1 \times$ TBS for 60 minutes at room temperature. The cells were then washed three times with $1 \times$ TBS and incubated with species-specific secondary Alexa Fluor antibodies (Thermo Fisher Scientific Inc., Waltham, MA) diluted in $1 \times$ TBS at room temperature for 2 hours in the dark. Finally, the cells were washed once with $1 \times$ TBS, incubated for 5 minutes with $300 \mu \mathrm{M} 44^{\prime}, 6$-diamidin-2phenylindol (cat. no. D1306; Thermo Fisher Scientific Inc.) in $1 \times$ TBS and then washed once again with $1 \times$ TBS. Imaging was performed using an Opera HCA reader (PerkinElmer) using a 405-nm and a 561-nm laser.

\section{Crystallization and Data Collection}

Crystallization and data collection were carried out as described in the Supplemental Material.

\section{Structure Solution and Refinement}

Structure solution and refinement were carried out as described in the Supplemental Material.

\section{Data Analysis}

Data analysis was carried out as described in the Supplemental Material.

\section{Results}

Selectivity of AB2 and AB20 for TrkB Isoforms. The selectivity of $\mathrm{AB} 2$ and $\mathrm{AB} 20$ was analyzed in three $\mathrm{CHO}$ cell lines that recombinantly overexpressed TrkA, TrkB, or TrkC. The response of the three cell lines was measured using the Alpha format. This Alpha assay quantified the phosphorylation of a homologous tyrosine (corresponding to Tyr706 or TrkB) in the cytoplasmic domain of all three Trk isoforms. Although NGF and NT3, physiologic agonists of TrkA and TrkC, respectively, induced the efficient phosphorylation of the respective tyrosine in their cognate receptors, neither $\mathrm{AB} 2$ nor AB20 produced any detectable pTrkA or pTrkC (Fig. 1, A and $\mathrm{C})$. In contrast, both $\mathrm{AB} 2$ and $\mathrm{AB} 20$ generated a clear phosphorylation of Tyr706 in the TrkB-overexpressing CHO cells (Fig. 1B). Hereby, AB2 displayed a molar potency similar to that of BDNF, and AB20 displayed a significantly weaker molar potency than BDNF (Table 1; Supplemental Fig. 1). The maximal extent of TrkB phosphorylation after AB2 or AB20 
A
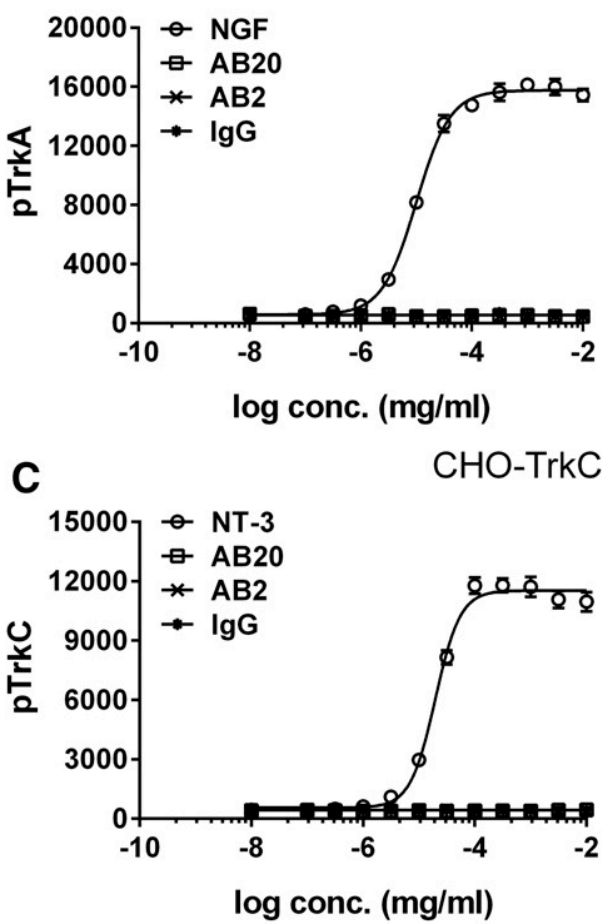

B CHO-TrkB
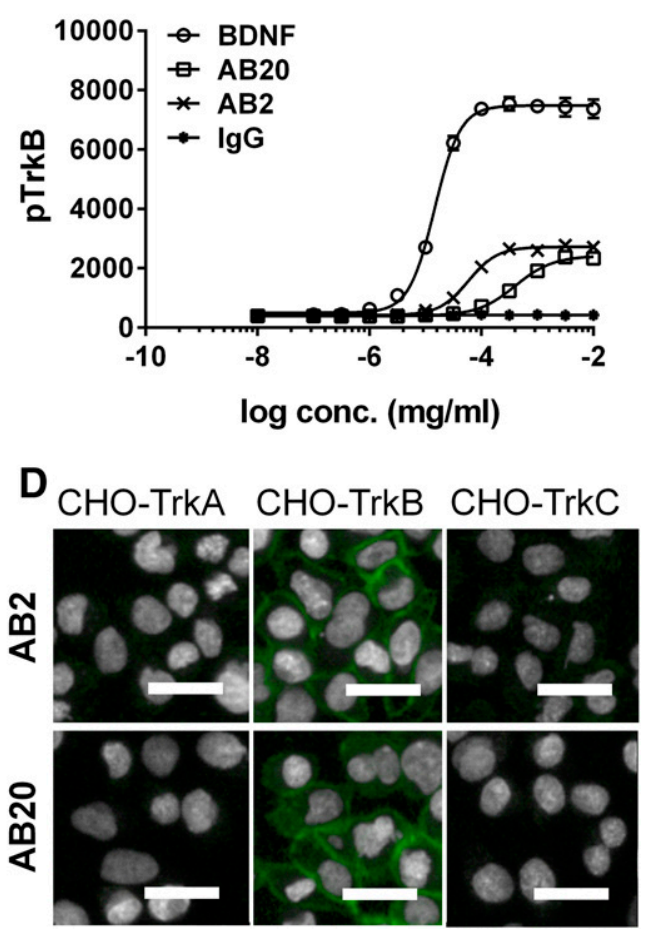

Fig. 1. Isoform selectivity of TrkBdirected antibodies $\mathrm{AB} 2$ and $\mathrm{AB} 20$. Dose-response testing was carried out in three $\mathrm{CHO}$ cell lines, recombinantly overexpressing (A) TrkA, (B) TrkB, and (C) TrkC. The cells were stimulated with $\mathrm{AB} 2, \mathrm{AB} 20$, or control IgG. As positive controls, the physiologic agonists NGF, BDNF, or NT-3 of the respective Trk isoforms were used. Potency and efficacy values for (B) are given in Table 1. $n=8$ replicates, error bars represent S.E.M. (D) Immune staining using $\mathrm{AB} 2$ and $\mathrm{AB} 20$ as primary antibodies was done on the same three cell lines: antibodies labeled in green, nuclear stain shown in white. Scale bar: $25 \mu \mathrm{M}$. administration was, however, significantly lower than the amount of pTrkB after maximal BDNF stimulation (Table 1; Supplemental Fig. 1). The finding of TrkB selectivity for AB2 and AB20 was further corroborated by an immunofluorescence study, in which the same two antibodies detected only epitopes in the TrkB-overexpressing but not in the TrkA- or TrkC-overexpressing, CHO cells (Fig. 1D). Selective TrkB activation was also reflected by an orthogonal Western blot analysis (Supplemental Fig. 2).

Transcriptional Modulation by BDNF, AB2, and AB20. NGS was used to monitor how BDNF, AB2, and
AB20 modulate the transcriptome of the hiPS cell-derived GRINCH neurons. In this study, 42 genes were selected as described in the Supplemental Material. Briefly, the selection was based on: 1) the absolute gene expression levels after $\mathrm{BDNF}, \mathrm{AB} 2, \mathrm{AB} 20$ or control IgG stimulation; 2) the degree of deregulation after agonist treatment; and 3) the false discovery rate.

Among these 42 genes, all 29 genes that were upregulated by BDNF were also upregulated by AB2 and AB20 (Fig. 2A). Likewise, all 13 genes that were downregulated by BDNF were also downregulated by AB2 and AB20. Hereby, the rank

TABLE 1

$\mathrm{EC}_{50}$ and relative efficacy values for $\mathrm{BDNF}, \mathrm{AB} 2$, and $\mathrm{AB} 20$ in the indicated TrkB signaling assays and using the indicated model cells

The $\mathrm{EC}_{50}$ values of $\mathrm{BDNF}, \mathrm{AB} 2$, and $\mathrm{AB} 20$ are given in $\mathrm{ng} / \mathrm{ml}$ and in $\mathrm{pM}$. The $95 \%$ confidence intervals $(95 \% \mathrm{CI}$ ) of the $\mathrm{EC}_{50}$ values are indicated. Assays in the CHO-TrkB cells and in the GRINCH neurons were carried out using $n=8$ and $n=4$ replicates, respectively.

\begin{tabular}{|c|c|c|c|c|c|c|c|}
\hline & & \multirow{2}{*}{$\frac{\text { CHO-TrkB }}{\text { pTrkB }}$} & \multicolumn{5}{|c|}{ GRINCH Neurons } \\
\hline & & & pTrkB & pERK & $\mathrm{pAKT}$ & pCREB & $V G F$ \\
\hline \multirow[t]{5}{*}{$\mathrm{BDNF}$} & $\mathrm{EC}_{50}(\mathrm{ng} / \mathrm{ml})$ & 15 & 0.67 & 0.20 & 0.33 & 0.13 & 0.41 \\
\hline & $95 \% \mathrm{CI}(\mathrm{ng} / \mathrm{ml})$ & $13 ; 16$ & $0.58 ; 76$ & $1.6 ; 2.6$ & $0.26 ; 0.42$ & $0.13 ; 0.16$ & $0.31 ; 0.55$ \\
\hline & $\mathrm{EC}_{50}(\mathrm{pM})$ & 540 & 25 & 7.4 & 12 & 4.7 & 15 \\
\hline & Efficacy (\%) & $100^{*}$ & $100^{*}$ & $100^{*}$ & $100 *$ & $100^{*}$ & $100 *$ \\
\hline & S.E.M. (\%) & 1.1 & 2.1 & 2.8 & 3.0 & 2.4 & 3.4 \\
\hline \multirow[t]{5}{*}{$\mathrm{AB} 2$} & $\mathrm{EC}_{50}(\mathrm{ng} / \mathrm{ml})$ & 59 & 10 & 5.1 & 4.6 & 1.1 & 2.5 \\
\hline & $95 \% \mathrm{CI}(\mathrm{ng} / \mathrm{ml})$ & $50 ; 68$ & $7.0 ; 15$ & $3.9 ; 6.7$ & $2.8 ; 7.8$ & $0.58 ; 1.9$ & $2.1 ; 2.9$ \\
\hline & $\mathrm{EC}_{50}(\mathrm{pM})$ & 390 & 67 & 34 & 31 & 7.0 & 17 \\
\hline & Efficacy (\%) & 28 & 51 & 79 & 102 & 108 & 101 \\
\hline & S.E.M. (\%) & $1 ; 9$ & 4.7 & 4.3 & 7.3 & 7.3 & 2.5 \\
\hline \multirow[t]{5}{*}{$\mathrm{AB} 20$} & $\operatorname{EC} 50(\mathrm{ng} / \mathrm{ml})$ & 404 & 80 & 43 & 37 & 67 & 11 \\
\hline & $95 \%$ CI $(\mathrm{ng} / \mathrm{ml})$ & $340 ; 480$ & $57 ; 110$ & $32 ; 57$ & $30 ; 46$ & $49 ; 92$ & $8.6 ; 15$ \\
\hline & $\mathrm{EC}_{50}(\mathrm{pM})$ & 2700 & 530 & 290 & 250 & 450 & 73 \\
\hline & Efficacy (\%) & 32 & 46 & 72 & 91 & 182 & 113 \\
\hline & S.E.M. (\%) & 2.5 & 7.0 & 3.7 & 2.6 & 3.0 & 5.1 \\
\hline
\end{tabular}

Relative efficacy values and the respective S.E.M. values are given in \%, normalized to BDNF as a full agonist with $100 \%$, as indicated by the asterisk *. 

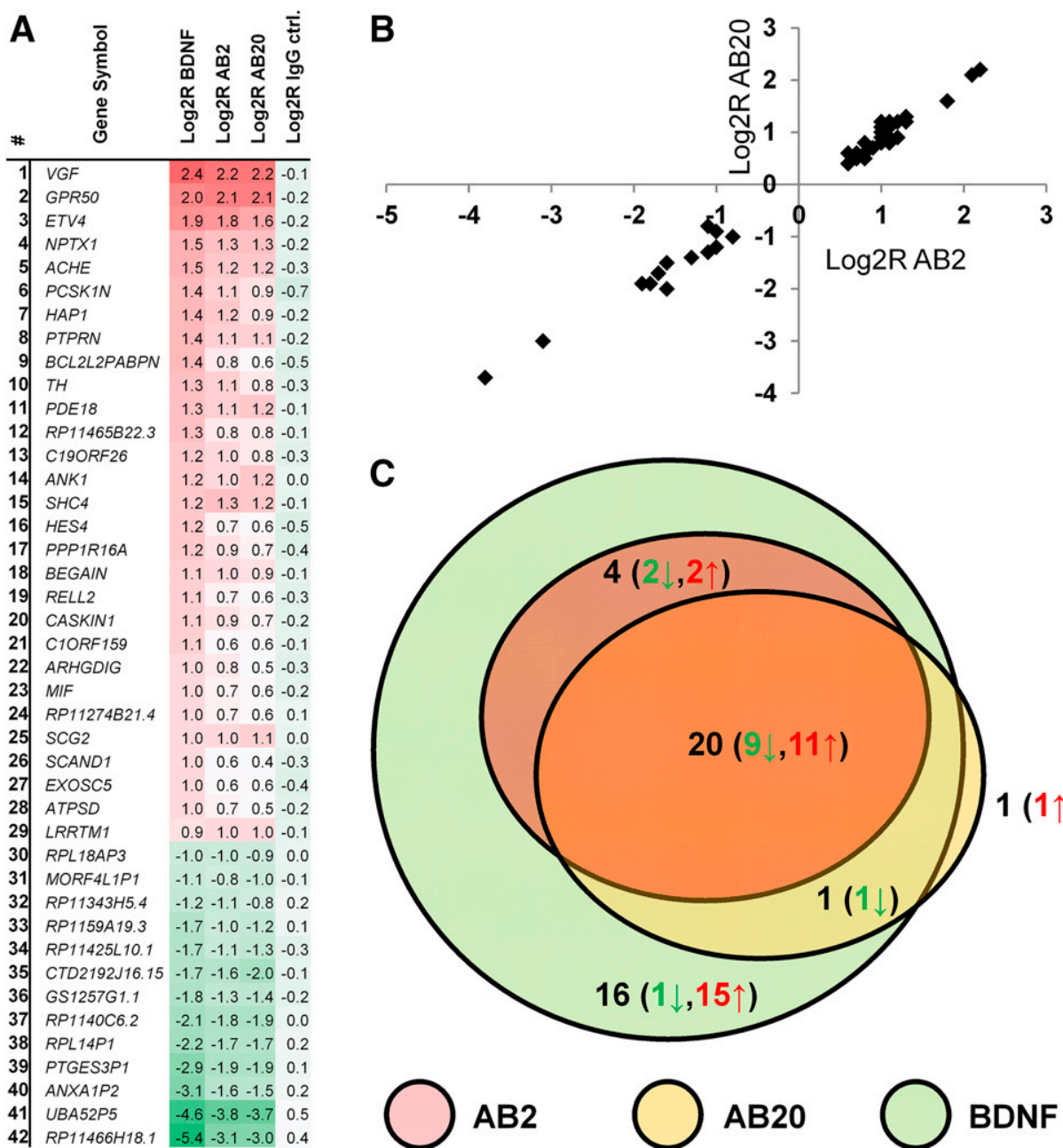

Fig. 2. Transcriptional modulation by BDNF, $\mathrm{AB} 2, \mathrm{AB} 20$, and IgG control in GRINCH neurons, analyzed by NGS. (A) 42 genes

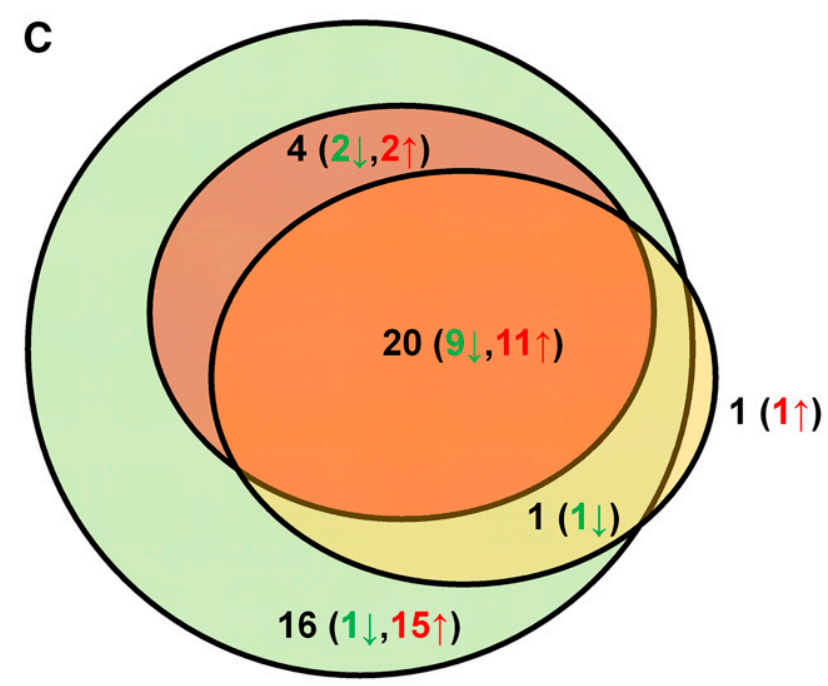
deregulated by $\mathrm{BDNF}, \mathrm{AB} 2$, or $\mathrm{AB} 20$ versus IgG control. The amplitude of deregulation is indicated by the Log2 $\mathrm{R}$ value. Red-coded numbers denote an upregulation, green-coded numbers a downregulation of gene expression. (B) $\log 2 \mathrm{R}$ values of the 42 genes deregulated by $\mathrm{AB} 20$ plotted versus the respective values for AB2. (C) Venn diagram. The numbers in the respective intersections designate the overlapping deregulated genes between the three agonists BDNF (green), AB2 (red), and AB20 (yellow). Red numbers designate upregulated genes, green numbers downregulated, and black numbers the sum of deregulated genes. $n=4$ replicates.

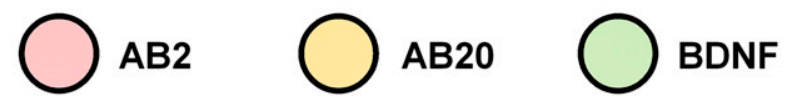

order of the fold changes was similar between BDNF versus control and AB2 versus control, as well as BDNF versus control and AB20 control. $V G F$, for instance, was the most upregulated gene for all three agonists; however, the amplitude of deregulation for several genes was higher for BDNF than for $\mathrm{AB} 2$ or $\mathrm{AB} 20$, for example, in regard to the upregulated genes BCL2L2PABPN, HES4, and RELL2, as well as the downregulated genes $A N X A 1 P 2$ and $R P 11466 H 18.1$ (Fig. $2 \mathrm{~A})$. In contrast, the amplitude of deregulation was quite similar between AB2 and AB20 (Fig. 2B).

In accordance with the described overlap of downstream signaling between BDNF and the two agonistic antibodies, the 24 genes that were at least 2 -fold deregulated by AB2 are a true subset of the 41 genes that were at least 2 -fold deregulated by BDNF (Fig. 2C). Likewise, 21 of the 22 genes that were at least 2-fold deregulated by AB20 are a subset of the 41 genes that were at least 2-fold deregulated by BDNF. In summary, AB2 and AB20 deregulated an overlapping gene set with BDNF, but BDNF acted as a more efficacious agonist than the two antibodies in regard to the amplitude of deregulation.

Modulation of TrkB Signaling Pathways by BDNF, AB2, and AB20. The stimulation of endogenous TrkB signaling by BDNF, AB2, and AB20 was measured using GRINCH neurons as model cells. Downstream signaling (Minichiello, 2009) was monitored with a focus on phosphorylation of ERK,
$\mathrm{AKT}$, and CREB, as well as on the expression of $V G F$ (Fig. 3A), an early response gene after NT receptor activation (Alder et al., 2003). In the pTrkB Alpha assay (Fig. 3B), BDNF, $\mathrm{AB} 2$, and $\mathrm{AB} 20$ displayed $\mathrm{EC}_{50}$ values (Table 1 ) of $0.67 \mathrm{ng} / \mathrm{ml}$ (25 pM), $10 \mathrm{ng} / \mathrm{ml}$ (67 pM), and $80 \mathrm{ng} / \mathrm{ml}$ (530 pM). Thus, all three agonists were significantly more potent in regard to the GRINCH neurons than to the TrkB overexpressing $\mathrm{CHO}$ (CHO-TrkB) cells (Table 1). Hereby, AB2 and AB20 were pronouncedly less efficacious in respect to TrkB phosphorylation than the physiologic agonist BDNF in both cell types: Both antibodies produced an approximately $30 \%$ maximal stimulation (normalized to the maximal stimulation by $\mathrm{BDNF}$ as 100\%) in the CHO-TrkB cells and approximately half-maximal stimulation in the GRINCH neurons (Table 1 ).

To explore the downstream efficacies of the TrkB agonists, Alpha assays were adapted to the GRINCH neurons, which selectively detected the phosphorylation of ERK, AKT, and CREB (Minichiello, 2009). In the assay for phosphorylated ERK (pERK; Fig. 3C), BDNF, AB2, and AB20 displayed potencies (Table 1) that were 2-to 3 -fold higher than with respect to phosphorylation of TrkB in the same cells; however, the rank order of potencies for the three agonists was the same between the pTrkB and the pERK signal, with $\mathrm{BDNF}>\mathrm{AB} 2>$ $\mathrm{AB} 20$. The relative efficacies for ERK phosphorylation of AB2 and $\mathrm{AB} 20$ were $79 \%$ and $72 \%$ compared with relative efficacies 


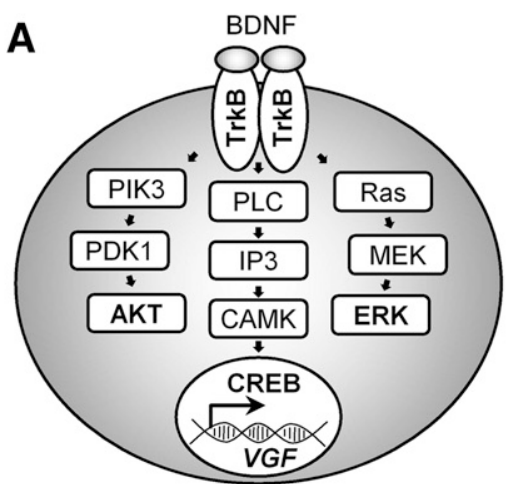

D

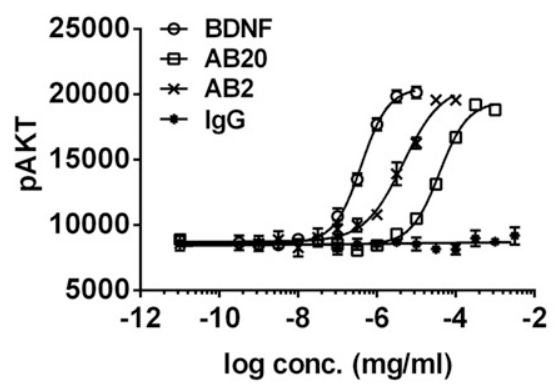

B

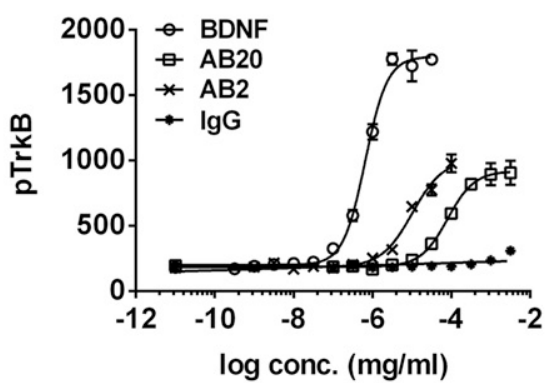

E

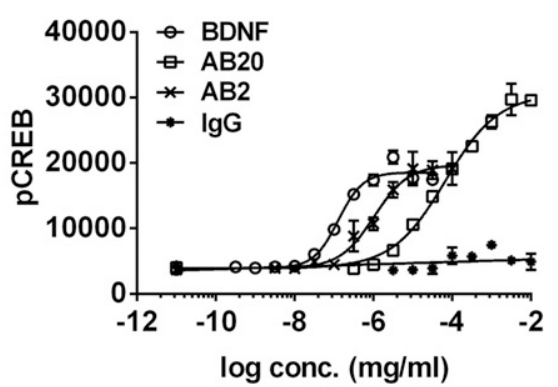

C
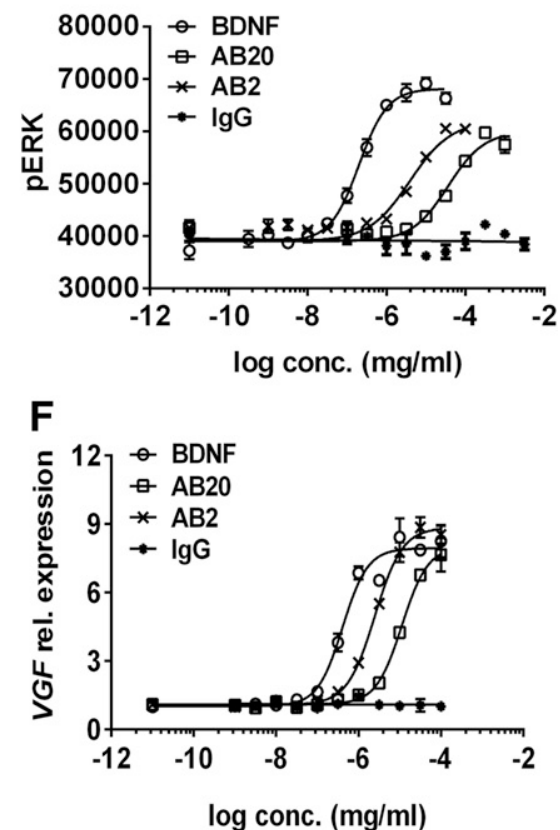

Fig. 3. TrkB-modulated signaling pathways in GRINCH neurons. (A) Dimeric BDNF stimulates TrkB dimerization. TrkB transphosphorylation leads to: 1) activation of AKT via PI3K and PDK1;2) activation of Ras, MEK, and ERK; 3) activation of CREB via activation of PLC, inositol triphosphate (IP3), and CAMK; 4) transcription activation of $V G F$. The agonist-modulated effects on phosphorylation are indicated by the measured Alpha values for (B) pTrkB, (C) pERK, (D) pAKT, and (E) pCREB. (F) RT-PCR data for the agonist-modulated effect on VGF expression based on $2^{\wedge}(-\Delta \mathrm{CP})$ values were normalized to vehicle-stimulated effects. Potency and efficacy values for (B-F) are given in Table 1. $n=4$ replicates; error bars represent S.E.M.

of $51 \%$ and $46 \%$, respectively, for the herein described TrkB phosphorylation (Table 1).

Potencies of all three agonists in the assay for phosphorylated AKT (pAKT) assay (Table 1; Fig. 3D) were quite similar to the potencies in the pERK assay, thereby maintaining also the same rank order of potencies as in the pTrkB assay. In regard to $\mathrm{AKT}$ phosphorylation, however, $\mathrm{AB} 2$ and $\mathrm{AB} 20$ were about equally efficacious agonists as BDNF (Table 1; Fig. 3D). The absolute potencies of the three agonists in regard to the signals for phosphorylated CREB (pCREB) were similar to the respective potencies for the described phosphorylation events (Table 1; Fig. 3E). Moreover, the rank order of potencies among the three TrkB agonists was once more maintained. Similar to the observations for the pAKT signal, AB2 displayed an efficacy comparable to that of BDNF in respect to CREB phosphorylation. As to AB20, this antibody even exceeded the efficacy of the physiologic agonist BDNF by a factor of approximately 1.8 .

Finally, the effect of the three agonists was investigated in the context of a TrkB-induced transcription event. As described for the NGS experiments (Fig. 2), the most extensive increase in transcription after TrkB activation was observed in regard to the $V G F$ gene. Consequently, the agonist-induced expression of the $V G F$ gene was monitored in GRINCH neurons using an RT-PCR assay (Fig. 3F). In line with all four of the herein described TrkB-modulated phosphorylation events, the three TrkB agonists stimulated $V G F$ transcription with picomolar potencies and with the same rank order of potencies. Similar to AKT phosphorylation, the efficacies of $\mathrm{AB} 2$ and $\mathrm{AB} 20$ were comparable to that of the physiologic agonist BDNF.
The pan-Trk kinase domain inhibitor K252a (Massa et al., 2010) inhibited all five of the here described agoniststimulated signaling events (Supplemental Fig. 3), endorsing the view that all observed agonistic effects are mediated by the Trk receptor. In further agreement with previously described TrkB-modulated signaling routes (Massa et al., 2010): 1) the mitogen-activated protein kinase kinase inhibitor PD98059 partially inhibited ERK phosphorylation, 2) the phosphatidylinositol 3 (PI3)-kinase inhibitor LY294002 decreased AKT phosphorylation, and 3) the phospholipase C inhibitor U73122 reduced phosphorylation of CREB for all three agonists (Supplemental Fig. 3).

Allosteric Binding Mode of AB20. BDNF binding to the TrkB immunoglobulin superfamily $\mathrm{d} 5$ domain was modeled on the previously published structures of: 1) the TrkB-d5 domain in complex with NT4/5 (Banfield et al., 2001) and of 2) the unliganded form of BDNF in a heterodimer with NT4 (Robinson et al., 1999). The validity of the TrkB-d5/BDNF model was further corroborated by the complex structure of the TrkA-d5 domain with NGF, which displayed homologous interaction sites between the NT and the receptor surface as observed for the complex between TrkB-d5 and NT4/5 (Banfield et al., 2001). Furthermore, affinity studies carried out between the Trk-d5 fragment and NT4/5 or BDNF have suggested that the NT binding site is located wholly within the d5 domain.

Whereas $\mathrm{AB} 2$ was known to act orthosterically with BDNF (Lin et al., 2010), AB20 was assumed to bind to a distinct epitope outside of the BDNF-binding site (Wang et al., 2010). Indeed, the described X-ray crystallography studies identified a complex structure of the BDNF-binding TrkB-d5 domain 
and AB20 (Fig. 4), with the binding epitope of AB20 localized at $\beta$-strands $\mathrm{C}, \mathrm{F}$, and $\mathrm{G}$ on the opposite side of the TrkB-d5 domain with respect to the BDNF binding site.

Synergies between BDNF and AB2 or AB20. To validate whether AB2 or AB20 exerted a synergistic effect with BDNF or with each other, a series of costimulation studies in the Alpha format was carried out using the GRINCH neurons as model cells. When AB2 was administered together with BDNF, maximal BDNF-driven phosphorylation of TrkB was reduced at high concentrations of AB2 (Fig. 5A). This observation is in accordance with the previously described competitive binding mode between $\mathrm{BDNF}$ and $\mathrm{AB} 2$ in regard to TrkB. In contrast to AB2, high concentrations of AB20 did not reduce the BDNF-driven phosphorylation of TrkB; however, no synergistic or additive effect was seen between $\mathrm{BDNF}$ and $\mathrm{AB} 20$ in regard to maximal stimulation, even at high AB20 concentrations (Fig. 5B). Likewise the $\mathrm{EC}_{50}$ value for the BDNF stimulation was not significantly altered by the presence of AB20.

As already described, AB2 and AB20 acted as partial agonists in regard to TrkB phosphorylation when applied individually (Table 1). In a costimulation experiment with both TrkB-directed antibodies, an additive effect was observed in regard to the maximal pTrkB signal (Fig. 5C). At the highest concentrations of both $\mathrm{AB} 2$ and $\mathrm{AB} 20$, the attained pTrkB signal was similar to the maximal stimulation obtained with BDNF. In regard to potency values, no significant synergistic effect was noted between AB2 and AB20.

Kinetics of TrkB Signaling Pathways after Stimulation with BDNF, AB2, or AB20. Using the Alpha formats as readouts, three different stimulation schemes (Fig. 6A) were applied to analyze how BDNF, AB2, and AB20 regulate the phosphorylation of TrkB, ERK, AKT, and CREB kinetically. For scheme I, referred to as restimulation, the indicated agonist was administered for a pulse period of 15 minutes,

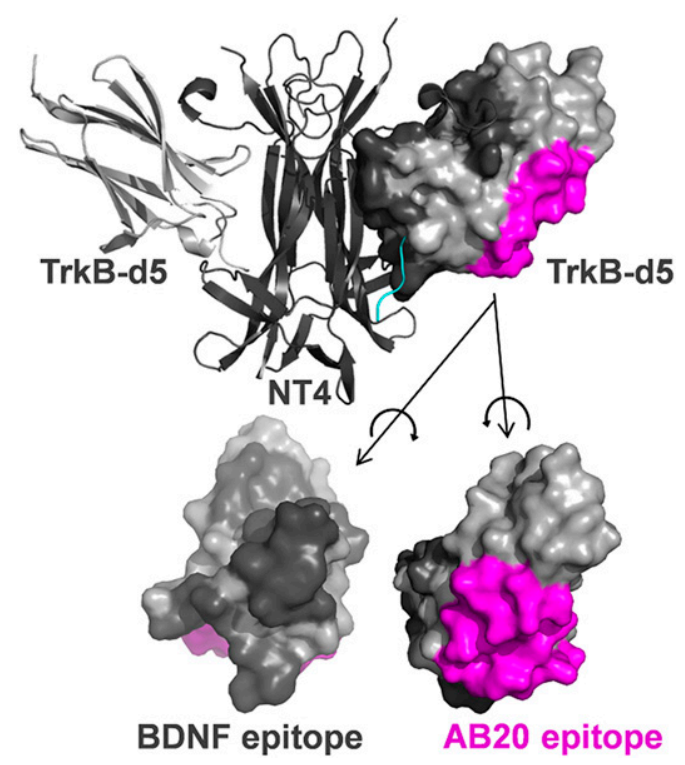

Fig. 4. Binding sites of BDNF/NT4 and AB20 on TrkB-d5 domain. The complex structure of the TrkB-d5 domain with AB20 was resolved by X-ray. The binding epitope of AB20 is labeled in pink. The binding site of BDNF (black) was modeled on the previously resolved complex structure of the TrkB-d5 domain with NT4. then washed off and readministered for a second pulse of 15 minutes at the end of the indicated time period. Using this scheme, the phosphorylation of TrkB, as well as of its downstream effectors ERK, AKT, and CREB, could be restimulated only by AB20 (Fig. 6B).

For scheme II, referred to as single-pulse stimulation, the indicated agonist was administered for a pulse period of 15 minutes, washed off, and then omitted from the cell supernatant for the remainder of the indicated time. In the first 6.5 hours after single-pulse stimulation, the BDNF-stimulated Alpha signals for pTrkB, pERK, and pAKT maintained a higher level than the respective AB2- or AB20stimulated signals (Fig. 6C). In the same time frame, the AB2stimulated Alpha signals for pTrkB, pERK, and pAKT were higher than the respective AB20-stimulated signals. In regard to pCREB signal kinetics, hardly any differences were seen between stimulation by BDNF or AB2; however, the level of pCREB generated by $\mathrm{AB} 20$ was lower than that generated by $\mathrm{BDNF}$ or $\mathrm{AB} 2$ during 2.5 hours after the single-pulse stimulation.

For scheme III, referred to as continuous stimulation, the specified agonist was administered at the beginning and then remained in the cell supernatant for the remainder of the indicated time. For time periods up to 2 hours, the BDNF-stimulated Alpha signals for pTrkB, pERK, and pAKT were higher than the respective signals with AB2 or AB20 stimulation (Fig. 6D). Only in regard to the pCREB signal did the AB20 stimulation provide higher Alpha signals than $\mathrm{BDNF}$ or $\mathrm{AB} 2$ for all analyzed incubation periods.

\section{Discussion}

The purpose of this work was to characterize two TrkBdirected antibodies, AB2 and AB20, in terms of pharmacology and downstream signaling using the physiologically relevant GRINCH neurons as a cellular model.

The binding selectivity of $\mathrm{AB} 2$ and $\mathrm{AB} 20$ for the TrkB isoform was supported by immunofluorescence investigation, where both antibodies immune-stained the TrkBoverexpressing, but not the TrkA- or TrkC-overexpressing, CHO cells. Likewise, a functional selectivity of these two antibodies was observed using the same three CHO cell lines recombinantly overexpressing one of the Trk receptors, NGF and NT3, and the physiologic agonists of TrkA and TrkC, respectively, stimulated Trk phosphorylation in $\mathrm{CHO}$ cells that were transfected with TrkA or TrkC, respectively. Neither AB2 nor AB20 was capable of inducing Trk activation in the latter two cell lines. In contrast, both AB2 and AB20 were capable of functionally activating Trk phosphorylation in the $\mathrm{CHO}$ cells that overexpressed TrkB; however, the maximal extent of AB2- or AB20-driven phosphorylation of TrkB was significantly lower than the efficacy of the BDNF-driven response in both the TrkB-overexpressing $\mathrm{CHO}$ cells and the GRINCH neurons.

Similar to the dimeric physiologic agonist BDNF, both TrkB-directed antibodies are supposed to be capable of inducing TrkB receptor dimerization (Cazorla et al., 2011). BDNF may, however, lead to a functionally preferred dimer arrangement that is more conducive to, for instance, receptor transphosphorylation (Cazorla et al., 2011). Concerning AB20, the latter hypothesis was corroborated by the herein described 

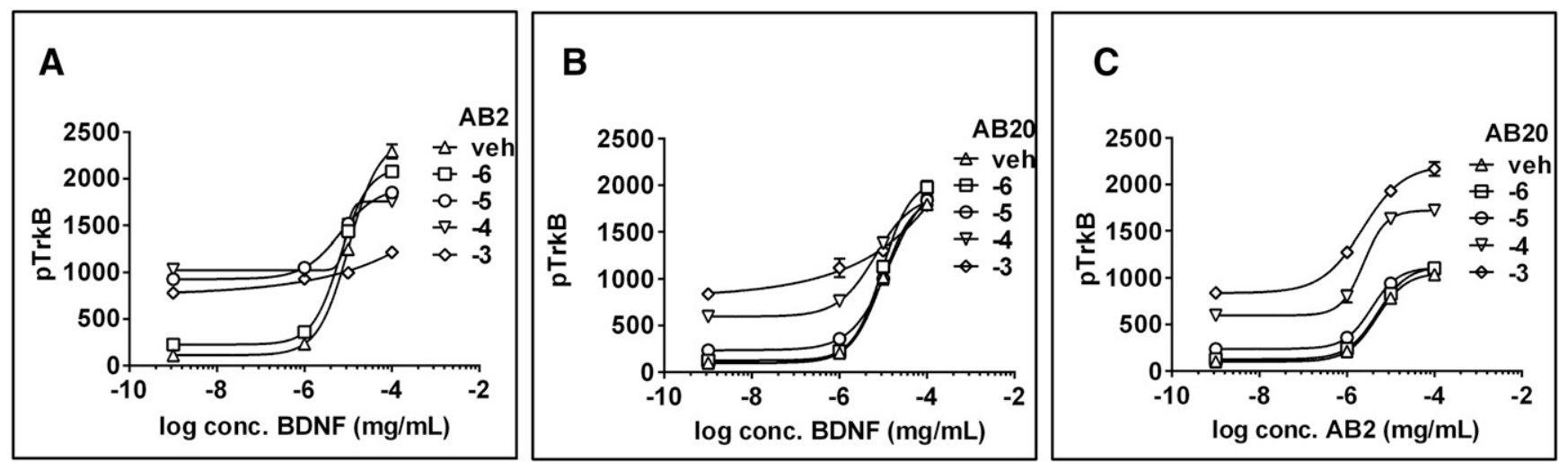

Fig. 5. Costimulation by pairs of TrkB agonists. GRINCH neurons were costimulated by (A) BDNF and AB2, (B) BDNF and AB20, as well as (C) AB2 and $\mathrm{AB} 20$. One of the two agonist concentrations is given on the $x$-axis; the second costimulatory agonist concentration is indicated by the symbol (with the respective decadic logarithm of the mass concentration $(\mathrm{mg} / \mathrm{ml})$ indicated in the legend; the "veh" curve represents the use of vehicle instead of second agonist). $n=6$ replicates; error bars represent S.E.M.

X-ray structure, where this antibody binds TrkB on the opposite site of the TrkBd5 domain compared with the presumable BDNF binding site. Yet, also for AB2, for which the binding site on TrkB overlaps with that of BDNF, the steric relationship and euclidean distance of the two TrkB protomers may be quite different from the BDNF-induced physiologic receptor dimerization.

Apart from presumably rendering the TrkB dimer less suitable for transphosphorylation, the AB2- or AB20induced spatial relationship of the TrkB protomers may modulate the accessibility of the intracellular phosphorylation sites in regard to further kinases that accept TrkB as a substrate (Huang and McNamara, 2010). Accordingly, such different agonist-dependent TrkB-dimeric structures may also result in diversely efficacious downstream signaling. This could explain why AB2 and AB20 displayed lower efficacies than BDNF also in regard to TrkB-modulated ERK phosphorylation and why AB20 appeared to be more efficacious than BDNF or AB2 in respect of CREB phosphorylation. Notably, a similar partial agonism of some commercially available TrkB-directed antibodies compared with BDNF as a full agonist had been observed previously (Cazorla et al., 2011). The partial efficacy of AB2 and AB20 in comparison with BDNF was also reflected by NGS experiments in which the amplitude of deregulation for most of the monitored genes was higher for BDNF than for the two agonistic antibodies.

In the work of Todd et al. (2014), the signaling efficacies of two different TrkB-agonistic antibodies were similar to BDNF after a 5-hour incubation period. Likewise, Qian et al. (2006) established five TrkB-directed antibodies that all stimulated TrkB-dependent luciferase signaling after an incubation of 16 hours to an extent similar to that of BDNF. Correspondingly, $\mathrm{AB} 2$ and $\mathrm{AB} 20$ in this work displayed similar efficacies as BDNF, for example, in the VGF transcription readout after a 6 -hour incubation. Hereby, the signal accumulation over the incubation period of several hours may mask a partial agonism of an antibody as observed for the respective phosphorylation measurements after incubation periods of 15 minutes.

Additionally, AB2 and AB20 displayed similar maximal effects as BDNF with respect to AKT phosphorylation, despite the agonist incubation time of 15 minutes. To explain this finding, one needs to consider that for some of the downstream TrkB-dependent signaling events other upstream members of the signaling chain might constitute the bottleneck of efficacy. In consequence, more efficacious pTrkB stimulation by BDNF than by $\mathrm{AB} 2$ or $\mathrm{AB} 20$ will not necessarily translate into a higher downstream readout. In agreement with this view, a broad overlap of the deregulated gene sets induced by any of the three here investigated agonists was observed in the NGS experiments. These observations argue against highly divergent ligand-biased signaling routes between BDNF, AB2, and AB20. In summary, the therapeutic value of an antibody with increased efficacy with respect to an upstream signaling event will depend on the translation of this efficacy into disease-relevant downstream events. For instance, AB2 and AB20 drove expression of the synaptic plasticity marker activity-regulated cytoskeleton-associated protein with, to some extent, lower efficacy than BDNF in rat primary neurons (Supplemental Fig. 4). Arc is an immediate-early gene, transcribed in response to neuronal activation. The newly translated protein is believed to play a critical role in learning and memory-related molecular processes (McIntyre et al., 2005). In GRINCH neurons, administration of BDNF, AB2, or AB20 over 7 days produced an approximately 2.5- to 3-fold increase in the VGF mRNA level without any significant efficacy differences between the three agonists (Supplemental Fig. 5).

The X-ray structure with the AB20-binding epitope on the opposite side of the $\mathrm{d} 5$ domain compared with the BDNF or AB2 binding site held out the prospect of synergistic TrkB activation. Indeed, AB2 and AB20 displayed additive effects on TrkB phosphorylation in GRINCH neurons; however, the maximal effect of the costimulation with both TrkB-directed antibodies did not exceed the maximal pTrkB signal as attained after solely stimulating with BDNF.

In contrast to the additive effects observed between $\mathrm{AB} 2$ and $A B 20$, no significant synergism in regard to the pTrkB signal was observed in a costimulation approach with AB20 and BDNF using the same model cells. One explanation for this finding might be that the more potently induced BDNFdriven TrkB activation leads to a receptor dimer that is 
A
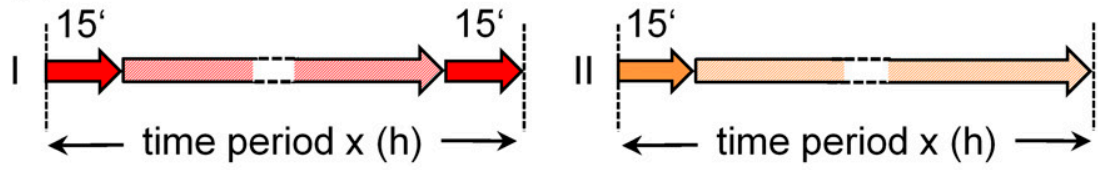

III

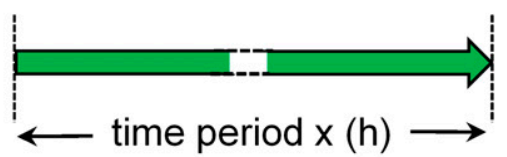

B

C

D
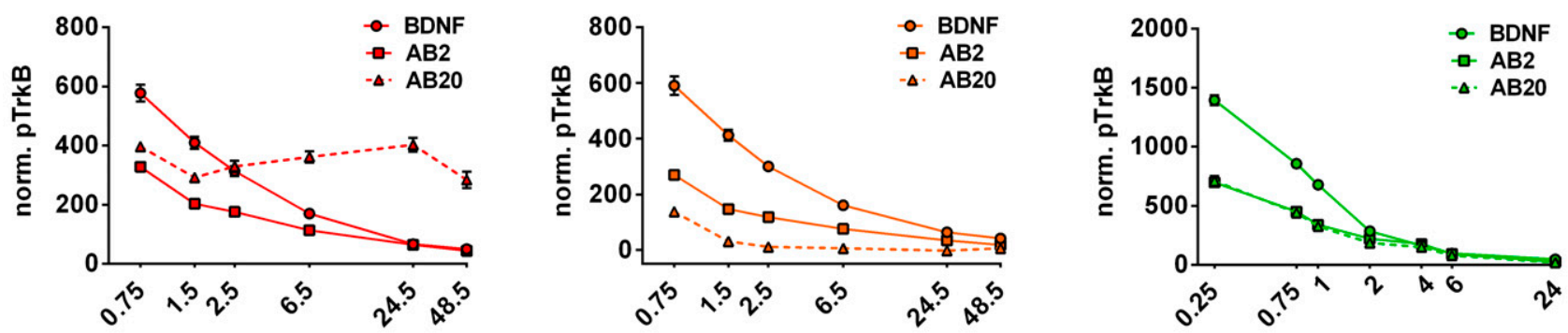

time period $x(h)$

time period $x(h)$
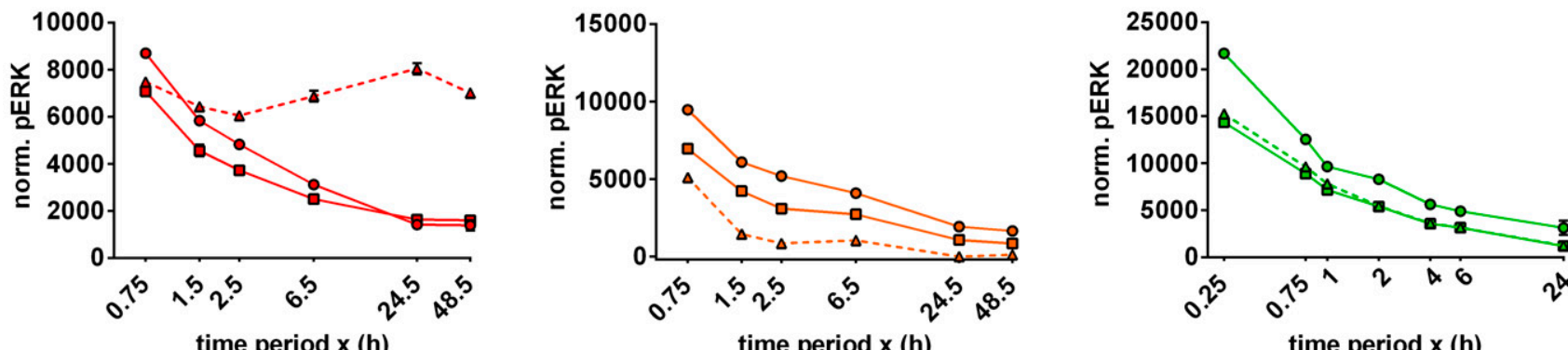

time period $x(h)$
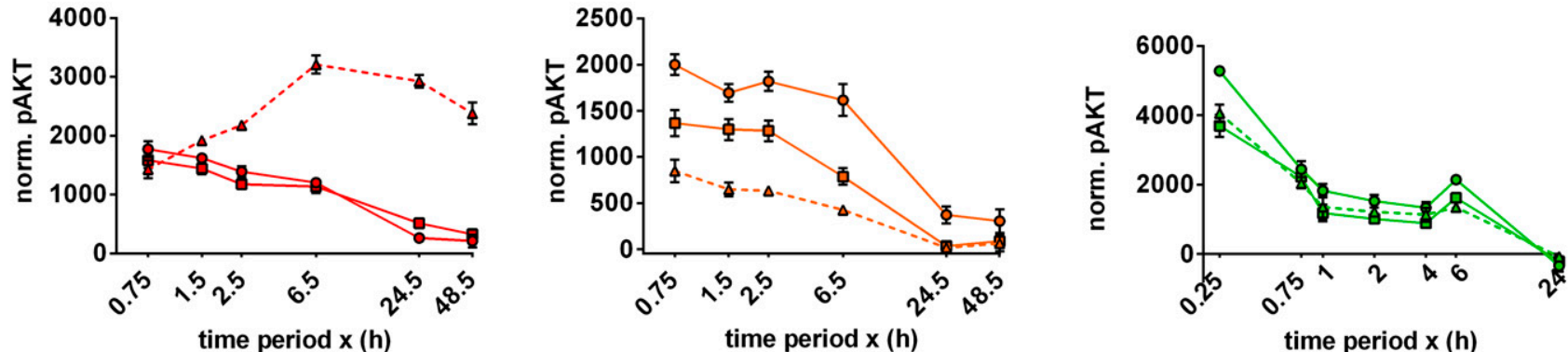

time period $x(h)$
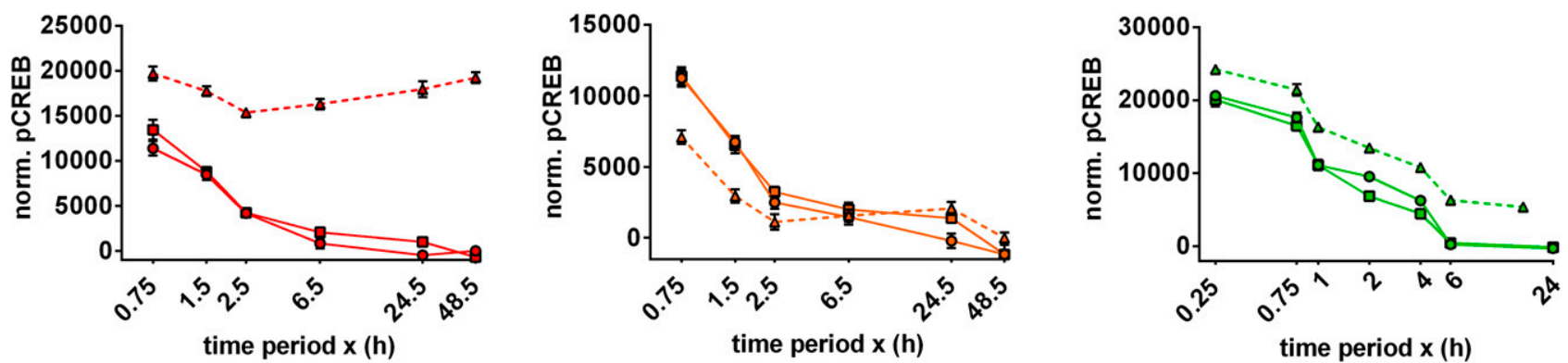

Fig. 6. Kinetics of TrkB signaling pathways after stimulation with BDNF, AB2, or AB20. TrkB stimulation was carried out using one of three (A) agonist administration schemes I-III; filled arrows indicate time spans with agonist in the cell supernatant; striped arrows indicate time periods after washing off the agonist from the cell supernatant. GRINCH neurons were stimulated according to schemes I, II, or III in (B), (C), or (D), respectively. The agonist-modulated effects on phosphorylation are shown as the measured Alpha values for pTrkB, pERK, pAKT, and pCREB, as indicated. Alpha signals are normalized to vehicle control. $n=8$ replicates; error bars represent S.E.M.

spatially incompatible with the AB20-induced dimer. In consequence, BDNF dominates the $\mathrm{pTrkB}$ effect in costimulation experiments with AB20. Finally, the BDNF-stimulated phosphorylation of TrkB was inhibited at high concentrations of $\mathrm{AB} 2$, which is in good agreement with the supposedly overlapping binding sites of $\mathrm{BDNF}$ and $\mathrm{AB} 2$. 
A restimulation approach was carried out on the GRINCH neurons with two 15-minute pulses of agonist administration, the first before and the second after a gap period without agonist in the cell supernatant. With increasing length of the agonist-free intermittent period, the BDNF- or AB2-driven Alpha signals for pTrkB, pERK, pAKT, and pCREB declined. Only AB20 led to an increased or at least maintained signal in all four phosphorylation assays after longer agonist-free gap periods. One possible explanation is that both $\mathrm{BDNF}$ and $\mathrm{AB} 2$ caused receptor internalization, whereas AB20 might have stimulated the phosphorylation of TrkB and downstream signaling without downregulating the receptor from the cell surface. If the receptor remains at the plasma membrane, the extracellular agonist may dissociate into the cell supernatant in the intermittent periods, thereby unblocking the ligand binding site of TrkB for a renewed stimulation during the second agonist pulse.

Such an explanation is in concordance with results of the single-pulse stimulation experiments, where the decline of pTrkB, pERK, pAKT, and pCREB was most pronounced after AB20 stimulation: If TrkB remains at the plasma membrane, AB20 may dissociate into the agonist-free supernatant and thereby diminish the activation state of the receptor. This working hypothesis is also in agreement with the findings in the continuous-stimulation experiment: If TrkB-dissociated AB20 can be replenished from the cell medium during the whole course of the experiment, the signal decrease during continuous $\mathrm{AB} 20$ administration should be similar to the signal decline during permanent $\mathrm{AB} 2$ exposure. Indeed, the Alpha signals between $A B 20$ and $A B 2$ in respect to pTrkB, $\mathrm{pERK}$, and pAKT were virtually identical in the continuous stimulation mode. In regard to CREB phosphorylation, the Alpha signal stimulated by AB20 was even higher than that induced by $\mathrm{BDNF}$ or $\mathrm{AB} 2$ for all observed time points. In all the kinetic experiments described here, the contribution of a potential agonist-stimulated novel synthesis in regard to TrkB, ERK, AKT, and CREB cannot be estimated. Accordingly, the measured concentrations of phosphorylated signaling proteins cannot be recalculated into a relative value of percent phosphorylation.

The use of GRINCH neurons as model cells for the pharmacologic studies provided several benefits. Thus, transcriptional and immunofluorescence-based analysis showed these hiPS-derived cells to be a balanced mixture of various neuronal subtypes, including particular cortical neurons, the latter cells being of particular relevance to study diseaserelevant TrkB pharmacology (Traub et al., 2017). Practically, the use of these model cells profited from the option to transiently freeze their neural precursor cells, from which the GRINCH neurons can be derived by a small-moleculeaccelerated, 2-week neuronal differentiation protocol.

Pharmacologic modulation of TrkB holds out the prospect of addressing various neurologic diseases. In this work, two previously described TrkB-agonistic antibodies were compared with BDNF activity in terms of TrkB receptor selectivity, potency, and efficacy. Both antibodies were found to be TrkB isoform selective. Both AB2 and AB20 displayed potencies in the picomolar range in regard to the various herein described pharmacologic readouts. In regard to some of the TrkB-modulated signaling events, neither AB2 nor AB20 attained the same maximal effect as the physiologic agonist
BDNF. If this partial agonism of the antibodies translates into an attenuated in vivo therapeutic effect, the respective cellular assay formats will be important tools for further optimization of the drug candidates. Likewise, the in vitro observed differences in restimulation kinetics may turn out to be predictive for in vivo tachyphylactic drug effects. As antibodies generally cross the BBB only to a limited extent, an appropriate trans-BBB shuttle system (Pardridge, 2012) may be required to render $\mathrm{AB} 2$ and $\mathrm{AB} 20$ valuable therapeutic tools for CNS disorders in the future. In summary, the developed techniques of pharmacologic analysis described here, together with the GRINCH neurons, open new experimental routes with tremendous potential for early TrkBdirected drug discovery.

\section{Acknowledgments}

The authors thank Dirk Stenkamp, Daniel Bischoff, Ulrike KüfnerMühl, Martin John Valler, Marcel Leist, Robert Ries, Tobias Hildebrand, German Leparc, Stefan Jäger, Natascha Piede, Michael Sulger, Achim Lietz, Anita Bloching, Margit Bauer, Kristina Vogel, Sebastian Bandholtz, and Rolf Herrmann.

\section{Authorship Contributions}

Participated in research design: Traub, Rosenbrock, Hospach, Hörer, Heilker.

Conducted experiments: Traub, Hospach.

Contributed new reagents or analytic tools: Stahl, Florin.

Performed data analysis: Simon.

Wrote or contributed to the writing of the manuscript: Traub, Stahl, Rosenbrock, Simon, Florin, Hörer, Heilker.

\section{References}

Adachi N, Numakawa T, Richards M, Nakajima S, and Kunugi H (2014) New insight in expression, transport, and secretion of brain-derived neurotrophic factor: implications in brain-related diseases. World J Biol Chem 5:409-428.

Alder J, Thakker-Varia S, Bangasser DA, Kuroiwa M, Plummer MR, Shors TJ, and Black IB (2003) Brain-derived neurotrophic factor-induced gene expression reveals novel actions of VGF in hippocampal synaptic plasticity. $J$ Neurosci 23: 10800-10808.

Banfield MJ, Naylor RL, Robertson AG, Allen SJ, Dawbarn D, and Brady RL (2001) Specificity in Trk receptor:neurotrophin interactions: the crystal structure of TrkBd5 in complex with neurotrophin-4/5. Structure 9:1191-1199.

Barde YA, Edgar D, and Thoenen H (1982) Purification of a new neurotrophic factor from mammalian brain. EMBO $J$ 1:549-553.

Bothwell M (2014) NGF, BDNF, NT3, and NT4. Handb Exp Pharmacol 220:3-15.

Cauchon E, Liu S, Percival MD, Rowland SE, Xu D, Binkert C, Strickner P, and Falgueyret JP (2009) Development of a homogeneous immunoassay for the detection of angiotensin I in plasma using AlphaLISA acceptor beads technology. Anal Biochem 388:134-139.

Cazorla M, Arrang JM, and Prémont J (2011) Pharmacological characterization of six trkB antibodies reveals a novel class of functional agents for the study of the BDNF receptor. Br J Pharmacol 162:947-960.

Heilker R, Traub S, Reinhardt P, Schöler HR, and Sterneckert J (2014) iPS cell derived neuronal cells for drug discovery. Trends Pharmacol Sci 35:510-519.

Huang YZ and McNamara JO (2010) Mutual regulation of Src family kinases and the neurotrophin receptor TrkB. J Biol Chem 285:8207-8217.

Lin CY, Chaparro Riggers JF, Grishanin RN, Stratton JR, and Zhai W(2010) Agonist anti-TrkB monoclonal antibodies. US patent 20100196390A1. 2010 Feb 1.

Longo FM and Massa SM (2013) Small-molecule modulation of neurotrophin receptors: a strategy for the treatment of neurological disease. Nat Rev Drug Discov 12: 507-525.

Massa SM, Yang T, Xie Y, Shi J, Bilgen M, Joyce JN, Nehama D, Rajadas J, and Longo FM (2010) Small molecule BDNF mimetics activate TrkB signaling and prevent neuronal degeneration in rodents. J Clin Invest 120:1774-1785.

McIntyre CK, Miyashita T, Setlow B, Marjon KD, Steward O, Guzowski JF, and McGaugh JL (2005) Memory-influencing intra-basolateral amygdala drug infusions modulate expression of Arc protein in the hippocampus. Proc Natl Acad Sci USA 102:10718-10723.

Minichiello L (2009) TrkB signalling pathways in LTP and learning. Nat Rev Neurosci 10:850-860.

Pardridge WM (2012) Drug transport across the blood-brain barrier. J Cereb Blood Flow Metab 32:1959-1972.

Qian MD, Zhang J, Tan XY, Wood A, Gill D, and Cho S (2006) Novel agonist monoclonal antibodies activate TrkB receptors and demonstrate potent neurotrophic activities. J Neurosci 26:9394-9403.

Robinson RC, Radziejewski C, Spraggon G, Greenwald J, Kostura MR, Burtnick LD, Stuart DI, Choe S, and Jones EY (1999) The structures of the neurotrophin 
4 homodimer and the brain-derived neurotrophic factor/neurotrophin 4 heterodimer reveal a common Trk-binding site. Protein Sci 8:2589-2597.

Todd D, Gowers I, Dowler SJ, Wall MD, McAllister G, Fischer DF, Dijkstra S, Fratantoni SA, van de Bospoort R, Veenman-Koepke J, et al. (2014) A monoclonal antibody TrkB receptor agonist as a potential therapeutic for Huntington's disease. PLoS One 9:e87923.

Traub S, Stahl H, Rosenbrock H, Simon E, and Heilker R (2017) Upscaling of hiPS cell-derived neurons for high-throughput screening. SLAS Discov 22:274-286.

Wang Y, Cohen SB, and Nasoff M (2010) inventors, Irm Llc, assignee. Agonist TrkB antibodies and uses thereof. U.S. patent 20100150914A1. 2007 Nov 7.
Xu D, Alegre ML, Varga SS, Rothermel AL, Collins AM, Pulito VL, Hanna LS, Dolan KP, Parren PW, Bluestone JA, et al. (2000) In vitro characterization of five humanized OKT3 effector function variant antibodies. Cell Immunol 200:16-26.

Address correspondence to: Dr. Ralf Heilker, Boehringer Ingelheim Pharma GmbH \& Co. KG, Lead Identification and Optimization Support, Birkendorfer Straße 65, D-88397 Biberach an der Riss, Biberbach, Germany. E-mail: Ralf.Heilker@boehringer-ingelheim.com 